МАХМУТОВА Евгения Викторовна - кандидат политических наук, доцент департамента политологии и массовых коммуникаций Финансового университета при Правительстве РФ (125993, Россия, г. Москва, ГСП-3, Ленинградский пр-кm, 49; EVMakhmutova@fa.ru)

\title{
ОСОБЕННОСТИ ИНТЕГРАЦИИ ИНОСТРАННЫХ СТУДЕНТОВ В РОССИЙСКОЕ ОБРАЗОВАТЕЛЬНОЕ ПРОСТРАНСТВО
}

\begin{abstract}
Аннотация. Современные тенденции образования приводят к глобализации всех его сфер. Одной из важных составляющих функционирования образовательной системы государства является академическая мобильность - свобода выбора университета независимо от места проживания. Россия сравнительно недавно приступила к улучшению своих показателей в этом направлении, несмотря на то что имеет многолетний советский опыт работы с иностранными студентами. В статье приводится анализ современного состояния этой сферы в России в контексте общемировых тенденций, оценивается имеющийся опыт привлечения студентов-иностранцев, рассматриваются основные сложности, с которыми сталкиваются иностранные студенты во время учебы в России. Автор приходит к выводу, что в целом ситуация на треке академической мобильности в России соответствует мировым показателям, популярность российских университетов по-прежнему высока (прежде всего, в региональном измерении). Однако решение государственной задачи повышения мирового престижа отечественных вузов требует качественно новых подходов в этом направлении.
\end{abstract}

Ключевые слова: образование, глобализация, иностранные студенты, английский язык, интернационализация вузов, постсоветское пространство

$\mathrm{B}$ условиях глобализации государство, обладающее теми или иными ресурсами, стремится интегрироваться в мировые политические и экономические структуры, занять свою нишу в системе международных отношений, выйти на мировой рынок, имея конкурентные преимущества в различных сферах [Иванова 2006: 58]. Одним из динамичных процессов глобализирующегося мира сегодня является образование - и как показатель влиятельности государства, и как инструмент его «мягкой силы». Важной частью процесса глобализации образования, что, собственно, и делает его универсальным и доступным независимо от проживания студента, является академическая мобильность возможность перемещения студентов из одной точки мира в другую для учебы в желаемом вузе [Лебедева, Фор 2009: 201].

Профессор А.С. Колесников из Института философии СпбГУ пишет, что «большинство мер, направленных на полномасштабное включение образования как сферы бизнеса в сеть глобальных и местных экономических взаимосвязей и взаимозависимостей, подобны приемам, характерным для экономики постиндустриального общества» [Колесников 2018: 56]. Именно в таком обществе образование постулируется как широкое пространство транснациональной культуры, в котором происходит борьба за потребителя образовательных услуг.

В настоящее время на мировом рынке образования можно назвать несколько наиболее активных игроков, занимающих ведущие позиции в различных профильных рейтингах. Бесспорным лидером по большинству критериев успеха образовательной модели являются США. Высокая востребованность американских вузов обусловлена множеством факторов, среди которых качество обучения, языковая доступность, современная материально-техническая база лабораторий и кампусов, возможность путешествовать по стране без языкового барьера. Совокупность этих параметров, а также высокие рейтинги и спрос на научные труды профессорско-преподавательского состава в академическом 
мире определяют неизменную популярность американских университетов среди студенческой молодежи по всему миру.

В списке лидеров также Великобритания, Китай, Австралия, Франция, Германия, Россия. Однако все перечисленные государства серьезно уступают США по одному из базовых показателей академической мобильности - числу принимаемых иностранных студентов. По данным pecypca Project Atlas, pacпределение позиций в списке ведущих стран по приему иностранных студентов выглядит следующим образом: США (26\%), Великобритания (12\%), Китай (11\%), Австралия (7\%), Франция (7\%), Россия (6\%), Германия (6\%), другие страны (25\%).

Стоит, правда, отметить, что в данном случае важно не только число студентов, но и страна - поставщик обучающегося контингента. Если в случае с англосаксонскими странами речь идет преимущественно о студентах из Азиатско-Тихоокеанского региона, то в случае с Россией основную экспортную силу составляют студенты стран постсоветского пространства. И в этой связи важно учитывать еще и причины, по которым иностранные студенты уезжают в другие страны на учебу (push-pull factors) [Eder, Smith, Pitts 2010: 233].

Одной из задач российской системы образования на современном этапе является интеграция в глобальное образовательное пространство, признание достижений российских ученых за рубежом, популяризация российских вузов среди иностранных студентов и профессуры.

Основным источником информации о российском высшем образовании для студентов-иностранцев служит официальный ресурс Министерства науки и высшего образования РФ Study in Russia. Авторы проекта сгенерировали информацию о программах, стипендиях, летних школах и обо всех организационных вопросах, связанных с обучением в России.

По данным Study in Russia, больше всего студентов традиционно приезжают из СНГ. Согласно последней по времени имеющейся статистике за 2016/2017 уч. г., число учащихся из этих стран возросло на $12 \%$ по сравнению с предыдущим учебным годом и составило 122 тыс. чел. Картина представительства всех студентов, обучающихся по очной и заочной форме, выглядит следующим образом. 1-е место занимает Азербайджан, доля которого составляет 89,8\%; 2-е место принадлежит Туркменистану (84,4\%); 3-е место - Армении (71\%). Если же посмотреть на очное обучение, т.е. где как раз важно физическое присутствие студента в стенах вуза и его адаптация к процессу обучения, то картина несколько иная. В данном случае заметное присутствие демонстрируют студенты из Центральной Азии - Казахстана (39 757 чел.), Туркменистана (17 264 чел.), Узбекистана (14 168 чел.) и Таджикистана (13 672 чел.). Причем в случае с Казахстаном можно говорить не только о традиционно близких политических, гуманитарных и социально-экономических отношениях между двумя государствами, но и о возможностях, которые предоставляет членство России и Казахстана в Евразийском экономическом союзе. 4-е место по числу студентов из СНГ с Узбекистаном делит Украина (13 653 чел.). Студентам из стран СНГ не нужно оформлять учебную визу.

Представители дальнего зарубежья приезжают в Россию с целью получения высшего образования в основном из Китая (26 775 чел.), Индии (9 845 чел.), Вьетнама (4 866 чел.), Монголии (2 989 чел.), Ирака, Марокко, Сирии, Египта, Нигерии, Эквадора, Колумбии, Бразилии. Как видно из статистики Миннауки, представительство студентов из стран Запада практически не просматривается. Безусловно, интерес к российскому образованию среди западных студентов также есть, это касается как Северной Америки, так и Европы. Однако в силу различных причин, в т.ч. и политического характера, представительство сту- 
дентов из этих регионов в разы меньше по сравнению с вышеназванными группами.

Такая структура иностранного студенчества, с одной стороны, является несомненным преимуществом для российских вузов, поскольку снимает многие сопутствующие трудности адаптации учащихся, такие как язык, культура, образовательные традиции. С другой - сохранение ориентации на постсоветское пространство сужает возможность для университетов России полноценно выходить на мировой уровень, сохраняет статус России как поставщика своих студентов в ведущие мировые вузы, а не реципиента.

Представленная картина наглядно демонстрирует тенденцию к «истернизации» потока студентов-иностранцев в Россию. Характерно, что страны, представленные в списке лидеров, в целом демонстрируют если не пророссийскую позицию на мировой арене, то, по крайней мере, лояльность или нейтралитет, в то время как молодежь из западных стран, с которыми у России напряженные отношения и где требуется особенно глубинная работа по налаживанию имиджа, мало представлена в российских вузах. Подобная ситуация напрямую влияет на формирование соответствующих программ обучения, в которых необходимо учитывать культурный код и «региональные» адаптационные возможности иностранных студентов стран (за исключением, возможно, студентов из СНГ, чей менталитет и чье погружение в среду может произойти гораздо быстрее в силу советского историко-культурного наследия, похожих программ и методик школьного образования, знания русского языка). В отличие от студентов из западных стран, «азиаты» кардинально отличаются и по культурному коду, и по национальным традициям. Именно понимание их национальных особенностей способствует более глубокой и быстрой адаптации к российским образовательным реалиям.

Российская программа академического превосходства реализуется в рамках проекта повышения конкурентоспособности ведущих российских университетов среди ведущих мировых научно-образовательных центров. Одним из критериев укрепления позиций России на мировом рынке образования является рост числа иностранных студентов в российских вузах как компонент интернационализации высшего образования. В рамках нацпроекта «Образование» стоит задача увеличения числа иностранных студентов к 2024 г. в российских вузах до 435 тыс. ${ }^{1}$ Так, в 2016/2017 уч. г. в российских вузах обучались 313,1 тыс. иностранных студентов ${ }^{2}$, из них 15 тыс. - по линии Россотрудничества, за счет российского бюджета ${ }^{3}$.

Здесь стоит отметить, что мировые рейтинги университетов, в критерии которых как раз и входит число иностранных студентов, имеют англосаксонские корни $(Q S$ и $T H E)$. Для вузов из незападного мира, в т.ч. и российских, попадание в топ подобных рейтингов (программа «5-100») представляется сложной, но в целом выполнимой задачей. В 2019 г. исследовательский центр Quacquarelli Symonds опубликовал новое издание рейтинга университетов QS World University Rankings. В него вошли 25 российских вузов, самое высокое место среди которых занял МГУ им. Ломоносова (84-е), на 244-м месте - Новосибирский госу-

\footnotetext{
${ }^{1}$ Национальный проект «Образование». - Министерство просвещения России. Доступ: https:// edu.gov.ru/national-project (проверено 07.01.2020).

2 Примечание: установленная квота с 2016 г. по н.вр.

3 Экспорт российских образовательных услуг: статистический сборник. Вып. 8. 2018. Министерство науки и высшего образования Российской Федерации. Доступ: http://socioprognozru.1gb.ru/files/File/2018/Arefiev_Sbornik_8_001_536_2018_ispr8_15_11_18.pdf (проверено 16.12.2019).
} 
дарственный университет. Также в данный рейтинг вошли еще 23 российских университета 1 .

Существующая наукометрическая система вхождения в мировые вузовские рейтинги, которая оценивает количественные, а не качественные показатели образования, существенно ограничивает возможности России занять высокие строчки в подобных перечнях ведущих университетов мира (прежде всего, США и Великобритании). Однако в региональном срезе российские вузы являются бесспорными лидерами. В 2019 г. $Q S$ предложил рейтинг вузов развивающихся стран Европы (к которым относит и Россию) и Центральной Азии, где первые три строчки занимают МГУ им. М.В. Ломоносова, СПбГУ и Новосибирский госуниверситет соответственно. На 8-м месте - Томский госуниверситет, на 11-м - Московский физтех, на $17-\mathrm{M}-$ ВШЭ и т.д. ${ }^{2}$ Из приведенной статистики видно, что среди вузов, имеющих близкие образовательные традиции, закрепленные общим прошлым, Россия лидирует. Однако в общемировой картине, особенно в свете конкуренции с западными образовательными моделями, которые сегодня в силу разных причин определяют академическую повестку, наблюдаются существенные противоречия.

Россия также разработала собственный международный рейтинг «Три миссии университета», идея которого заключается в том, чтобы сделать представительство российских вузов более широким и заметным ${ }^{3}$.

\section{«Мягкая сила» как важный инструмент образовательной стратегии России}

В России одной из задач интеграции зарубежного студенчества в национальную систему образования является конструирование позитивного образа страны за рубежом как часть инструментария «мягкой силы». Помимо очевидных финансовых преимуществ как для вуза, так и для государственного бюджета, которые несет в себе обучение студентов-иностранцев, ставка на эту категорию обучающихся имеет прикладное значение: она способствует формированию у студенческой молодежи объективного восприятия России, лояльного отношения к особенностям политической культуры, традициям, ценностным установкам и образу жизни в целом. Конечная цель - укрепление влияния России в мире, минимизация антироссийских действий на международных площадках, продвижение интересов России за рубежом.

Популяризацией русского языка среди иностранной молодежи занимается Государственный институт русского языка им. А.С. Пушкина. Он считается базовой организацией в СНГ по преподаванию русского языка. Еще один крупный проект - фонд «Русский мир», целью которого является популяризация русского языка, поддержка изучения русского языка и культуры в России и за рубежом. Фонд также реализует различные программы в российских вузах, например турнир по химии в МГУ, проект «Профессор русского мира», поддерживает международные образовательные форумы.

Интеграционными площадками для выпускников российских вузов являются Всемирная ассоциация выпускников высших учебных заведений, для студентов - Ассоциация иностранных студентов в России. Ассоциации выпускников советских и российских вузов созданы более чем в 70 странах мира на

\footnotetext{
${ }^{1}$ University rankings. - Top Universities. URL: https://www.topuniversities.com/university-rankings/ (accessed 16.12.2019).

2 University rankings. - Top Universities. URL: https://www.topuniversities.com/universityrankings/eeca-rankings/2020 awc $=10032 \_1571127765 \_7 f 9 c 5 b 5 b e 5 a 4 e 24 f 8312912 d 5833$ e7eb (accessed 16.12.2019).

3 Ректор МГУ презентовал рейтинг «Три миссии университета». - RAEX Rating Review. 19.09. Доступ: https://raex-rr.com/three_missions_rating_presentation (проверено 15.12.2019).
} 
общественном уровне и являются важным инструментом, работающим на основании выстроенных еще в советский период дружеских связей. Поэтому, в отличие от государственных структур, здесь удается выстроить диалог с молодежью в государствах, где представительства Россотрудничества нет или оно не имеет возможности активно работать на данном направлении. Например, недавно были открыты Ассоциации выпускников российских и советских вузов в Грузии и Литве ${ }^{1}$. Задача ассоциаций заключается в помощи тем выпускникам российских вузов, которые по возвращении на родину хотят продолжать взаимодействовать с Россией через землячества, открытие российских культурных центров и т.д. При этом работа по поиску подобных молодых людей идет еще на том этапе, пока они учатся в России. Основными критериями являются лидерский потенциал и активная общественная деятельность (руководящие посты в студенческих ассоциациях, землячествах, общественных организациях, волонтерство на значимых российских мероприятиях), а также участие в проектах Росмолодежи. Также инициатива поддержания контактов иностранных выпускников российских вузов друг с другом исходит и от самих вузов: ярким примером может послужить организация V Международного форума выпускников МГИМО в Ташкенте (Узбекистан) в мае 2019 г. ${ }^{2}$ На мероприятии собрались выпускники как советского, так и российского периода.

В целом, нужно признать, что землячества и ассоциации выпускников стали новым эффективным методом рекрутинга иностранных студентов, а также инструментом продвижения имиджа России за рубежом. Несмотря на то что на территории постсоветского пространства открыты 12 представительств и 9 филиалов Россотрудничества ${ }^{3}$, охватить весь фронт работы на данном направлении им не удается. Более того, метод «сарафанного радио» в данном случае работает лучше всего, т.к. потенциальные абитуриенты получают всю интересующую их информацию не от представительств вузов или государственных структур, а от тех, кто сам отучился, прошел путь социокультурной адаптации и готов поделиться своим опытом.

Еще одно направление работы с иностранной студенческой молодежью работа с ближайшими соседями. Тут Россия руководствуется двумя разными стратегиями. Одна из них связана с созданием региональных образовательных кластеров, ориентированных как на внутренний прием российских студентов, так и на приграничные регионы, а вторая ориентирована на те приграничные регионы, где в этническом соотношении широко представлено русское население. Примером первой стратегии можно считать Южно-Сибирский макрорегион, где привлечение иностранных студентов - одна из мер по преодолению демографических проблем, вызванных спадом рождаемости в 1990-х гг., оттоком российской молодежи из региона в столичные вузы. Примером второй стратегии можно считать Северный Казахстан, где наблюдается отток русскоязычных граждан в соседние российские регионы.

Российскому руководству выгодно, чтобы иностранные выпускники, получив опыт проживания в стране, познакомившись с ее социокультурными особенностями, оставались в России. Особенно этот вопрос актуален для малонаселенных регионов Сибири и Дальнего Востока. Данная стратегия косвенно

\footnotetext{
1 «Если мы не будем работать с иностранными студентами сегодня, то завтра выпускники не будут работать с нами». - Фонд «Русский мир». 14.06.2019. Доступ: https://russkiymir.ru/ publications/258245/ (проверено 07.01.2020).

2 V Международный форум выпускников МГИМО. - Ассоциация выпускников МГИМО. Доступ: http://www.alumniforum.mgimo.ru/ (проверено 07.01.2020).

3 Глава Россотрудничества назвала главной миссией расширение круга друзей РФ. Россотрудничество. 11.04. Доступ: http://rs.gov.ru/ru/medias/30 (проверено 07.01.2020).
} 
поддерживается и на государственном уровне - через политику предоставления гражданства, которая ориентирована на те приграничные регионы, где в этническом соотношении широко представлено русское население.

На современном этапе Россия использует данный подход для государств постсоветского пространства, а также для тех стран, где у России имеется стратегический интерес, ориентированный на долгосрочную перспективу: это государства Африки, Ближнего Востока. К последнему можно отнести Сирию: для сирийцев выделена одна из самых больших квот на обучение в России - 500 чел. При этом число заявок превышает 2500.

Значительный пласт работы в направлении популяризации русского языка и русской/российской культуры реализуется Россотрудничеством и на территории России. Привлечение иностранной молодежи для учебы в российских вузах - одна из центральных задач российского образования. В отличие от многочисленных западных программ образования, ставших хорошо узнаваемыми в мире, в России пока не сложился аналогичный устойчивый бренд, хотя работа на данном направлении в последние годы заметно активизировалась. Именно отсутствие широчайшего спектра академических программ, неразвитая система академической мобильности, которая только набирает обороты в России, не способствуют качественному притоку иностранных студентов в отечественные вузы.

Российское руководство совместно с университетами прилагает много усилий для привлечения иностранных студентов для обучения в России. Одна из таких опций - квотирование высшего образования. Более 15 тыс. студентов имеют возможность приехать в Россию и получать высшее образование бесплатно. Им предоставляется общежитие, а также все льготы, полагающиеся российским студентам. В целях повышения авторитета страны на международной арене предполагается увеличить квоты и тем самым способствовать большему притоку иностранных студентов. Образование в России можно получать как на русском, так и на других языках.

\section{Специфика российской образовательной модели для иностранцев}

Одна из главных проблем, с которой сталкиваются студенты-иностранцы в России, - языковой барьер, поскольку в рамках большинства направлений, особенно негуманитарных, занятия ведутся на русском языке. И хотя число англоязычных программ растет, проблема все равно остается одной из определяющих при выборе вуза. И если для студента из стран постсоветского пространства обучение на русском языке в большинстве случаев не является препятствием, то как раз для более широкой аудитории - западной или из стран Юго-Восточной Азии - это серьезная трудность. Российские вузы предлагают подготовительные языковые курсы, однако этого недостаточно для легкой адаптации студента из дальнего зарубежья.

Такая специфика российского образования имеет две грани. С одной стороны, остается недопонятой содержательная часть изучаемых дисциплин, вследствие чего у студента могут возникнуть сложности с адаптацией или даже разочарование в выбранных стране и вузе, а с другой - студент зачастую лишается возможности получить информацию и от административно-хозяйственного персонала, который редко владеет английским языком. В условиях поставленной государственной задачи повышения мирового престижа российского образования такая ситуация нуждается в дополнительном внимании.

Вторая проблема, которая имеет непосредственное отношение к первой, языковой барьер в общении вне стен университета. Согласно докладу компании EF (Education First), Россия занимает 48-е место из 100 в рейтинге владе- 
ния иностранным языком, что считается низким показателем ${ }^{1}$. На 1-м месте Нидерланды, на 47-м - Беларусь, на 49-м - Украина. Например, Китай, где также не распространена практика повсеместного владения иностранным языком и который также ставит перед собой задачу повышения мирового престижа своих университетов, занимает в этом рейтинге 40-е место. Однако в китайских вузах довольно жесткие требования к владению китайским языком, и без соответствующих сертификатов, подтверждающих хотя бы минимальный уровень знания китайского, поступить в местный университет невозможно.

Третья сложность, с которой часто сталкиваются многие иностранные студенты, - слабая адаптивность сайтов университетов к абитуриентам из-за рубежа. Российский совет по международным делам провел сравнительное исследование, посвященное изучению англоязычных сайтов российских вузов, сравнив их с ресурсами 11 ведущих мировых университетов из списка $Q S^{2}$. Исследование показало, что самыми проблемными являются такие разделы, как «Карьера», «Библиотека», «Выпускники», «Факультеты, институты, подразделения», «Основные показатели».

Подводя итоги работы с иностранными студентами в России, можно сделать следующие выводы.

1. Количественное измерение академической мобильности иностранных студентов в России в целом соответствует общемировым показателям. Россия ожидаемо уступает таким лидерам, как США и Великобритания, однако если брать страны второго (Германия, Франция) и последующих уровней, а также ведущие восточноевропейские вузы в Чехии, Польше, Венгрии, то она идет наравне или даже опережает их. Это позволяет утверждать, что академическая мобильность является одной из сильных сторон российского образования. Однако структура иностранцев, обучающихся в России, существенно отличается от большинства западных вузов, на которые принято ориентироваться в вопросе интернационализации образования. В Россию едут преимущественно студенты из постсоветского пространства, адаптационные условия для которых практически не нужно создавать.

2. Российская стратегия привлечения иностранных студентов в свои вузы многогранна и включает в себя работу как с нынешними студентами, так и с выпускниками. Еще одно направление работы - соотечественники, проживающие за рубежом. Большинство студентов едут на учебу в Россию либо по квотам, либо на платной основе и, как правило, не испытывают серьезных проблем с адаптацией.

3. Одна из главных сложностей с адаптацией иностранных студентов заключается в наличии языкового барьера как на уровне университета, так и в социальном окружении учащегося. Несмотря на растущее число программ на иностранном языке, а также обновление библиотечного фонда, эта проблема, помимо прочих, остается одной из значимых при выборе университета иностранными студентами из стран дальнего зарубежья.

Статья подготовлена по результатам исследований, выполненныхза счет бюджетных средств по государственному заданию Финуниверситету.

\footnotetext{
1 Рейтинг 100 стран и регионов по уровню владения английским языком. - Education First 2019. Доступ: https://www.ef.ru/_/ /media/centralefcom/epi/downloads/full-reports/v9/ef-epi2019-russian.pdf (проверено 15.12.2019).

2 Электронная интернационализация вузов. - Российский совет по международным делам. 2015. Доступ: https://russiancouncil.ru/digital-universities\#download (проверено 16.12.2019).
} 


\section{Список литературы}

Иванова 3.И. 2006. Сущность глобализации в рамках глобализационной парадигмы. - Гуманитарные науки, культура и образование: актуальные проблемы современности: сборник научных трудов. Саратов: Изд-во СГУ им. Н.Г. Чернышевского. С. 57-63.

Колесников А.С. 2018. Философско-методологические предпосылки новой парадигмы системы образования в условиях интеграции и глобализации. Социальная компетентность. № 3(4). С. 49-59.

Лебедева М.М., Фор Ж. 2009. Высшее образование как потенциал «мягкой силы» России. - Вестник МГИмО Университета. № 6(9). С. 200-205.

Eder J., Smith W.W., Pitts R.E. 2010. Exploring Factors Influencing Student Study Abroad Destination Choice. - Journal of Teaching in Travel and Tourism. Vol. 10. Is. 3. P. 232-250.

MAKHMUTOVA Evgeniya Viktorovna, Cand.Sci. (Pol.Sci.), Associate Professor at the Department of Political Science and Mass Communication, Financial University under the Government of the Russian Federation (49 Leningradsky Ave, GSP-3, Moscow, Russia, 125993; EVMakhmutova@fa.ru)

\section{SPECIFICS OF THE INTEGRATION PROCESS OF INTERNATIONAL STUDENTS TO THE RUSSIAN EDUCATIONAL SPACE}

Abstract. The comparative analysis shows that Russia has seriously opted for competition in global education market. There are several strong arguments for such strategy. Firstly, since the USSR, Russia has a positive image as a solid provider of high-quality education specifically in science, medicine, and construction. Today this Soviet heritage is supported by Soviet universities alumna associations, which are still in force in a number of countries. Secondly, Russian government has made significant efforts to improve its role in the global education space through revising its approach to attracting international students. Moreover, new instruments and new formats were used to make Russia's international educational activities more effective. Russian federal state universities were stimulated to develop their English language web sites to promote their educational capacities outside the country. Consequently, all these efforts have their positive impact on awareness raising of Russia's educational system. Thirdly, the economics of education is becoming a factor for Russian universities. The costquality ratio for a number of educational programs in Russian universities looks quite attractive for international students, especially from neighboring Asian countries.

What Russia is seriously lacking in the global competition for international students is a spread of English as a working language in universities. Another problem is unclear carrier perspectives for foreigners graduating from Russian universities. These obstacles prevent Russia from achieving a goal of gaining ground on the global market of higher education. Keywords: education, globalization, international students, English language, internationalization of universities, post-Soviet space 